\title{
Prevalence and correlates of inadequate glycaemic control: results from a nationwide survey in 6,671 adults with diabetes in Brazil
}

\author{
Ana Beatriz Valverde Mendes · João Antônio Saraiva Fittipaldi · \\ Raimundo Celestino Silva Neves • Antônio Roberto Chacra • \\ Edson Duarte Moreira Jr
}

Received: 13 May 2009/Accepted: 14 July 2009/Published online: 5 August 2009

(c) The Author(s) 2009. This article is published with open access at Springerlink.com

\begin{abstract}
Diabetes is a significant public health burden on the basis of its increased incidence, morbidity, and mortality. This study aimed to estimate the prevalence of inadequate glycaemic control and its correlates in a large multicentre survey of Brazilian patients with diabetes. A cross-sectional study was conducted in a consecutive sample of patients aged 18 years or older with either type 1 or type 2 diabetes, attending health centres located in ten large cities in Brazil (response rate $=84 \%$ ). Information about diabetes, current medications, complications, diet, and satisfaction with treatment were obtained by trained interviewers, using a standardized questionnaire. Glycated haemoglobin $\left(\mathrm{HbA}_{1 \mathrm{c}}\right)$ was measured by high-performance liquid chromatography in a central laboratory. Patients with $\mathrm{HbA}_{1 \mathrm{c}} \geq 7$ were considered to have inadequate glycaemic control. Overall 6,701 patients were surveyed, 979 (15\%)
\end{abstract}

This study is conducted for the "Brazilian Diabetes Investigators' Group". The members of the "Brazilian Diabetes Investigators' Group" are listed in "Appendix" section.

A. B. V. Mendes - A. R. Chacra

São Paulo Federal University, Rua Botucatu, 740,

São Paulo 04023-900, Brazil

J. A. S. Fittipaldi

Pfizer Inc., Rua Alexandre Dumas 1860,

Chácara Santo Antonio, São Paulo 04717-904, Brazil

R. C. S. Neves - E. D. Moreira Jr $(\bowtie)$

Gonçalo Moniz Research Center, Oswaldo Cruz Foundation,

Brazilian Ministry of Health, Rua Waldemar Falcão 121,

Salvador, Bahia 40296-710, Brazil

e-mail: edson@bahia.fiocruz.br

E. D. Moreira Jr

Clinical Research Center, Charitable Works Foundation of Sister

Dulce, Av. Bonfim 161, Salvador 40415-006, Brazil with type 1 and 5,692 (85\%) with type 2 diabetes. The prevalence of inadequate glycaemic control was $76 \%$. Poor glycaemic control was more common in patients with type 1 diabetes (90\%) than in those with type $2(73 \%)$, $P<0.001$. Characteristics significantly associated with improved glycaemic control included: fewer years of diabetes duration, multi professional care, participation in a diabetes health education program, and satisfaction with current diabetes treatment. Despite increased awareness of the benefits of tight glycaemic control, we found that few diabetic patients in Brazil met recommended glycaemic control targets. This may contribute to increased rates of diabetic complications, which may impact health care costs. Our data support the public health message of implementation of early, aggressive management of diabetes.

Keywords Glycaemic control $\cdot \mathrm{HbA}_{1 \mathrm{c}}$. Diabetes mellitus · Epidemiology · Brazil

\section{Introduction}

Diabetes is one of the most prevalent non-communicable diseases globally, presenting a significant public health burden on the basis of its increasing incidence, morbidity, mortality, and economic costs [1-3]. In 2000, estimates from World Health Organization indicated that there were $\sim 170$ million people in the world with diabetes, and until 2030 , it is expected that the number of cases of the disease worldwide will have more than doubled to 366 million [2]. In the Americas, the number of diabetes cases will change from 33 million to 66.8 million in the same period [2]. Diabetes is associated with serious long-term complications including microvascular and macrovascular disease, 
which impose an additional socio-economic burden and account for substantial healthcare costs [1, 3-6].

Evidence from key controlled studies conducted in the past decade established the importance of tight and sustained glycaemic control among type 1 and 2 diabetic patients [7, 8]. These studies have emphasized the central role of consistently managing $\mathrm{HbA}_{1 \mathrm{c}}$ levels in patients with diabetes, as a result, some professional associations proposed clinical guidelines in the range of $6.5-7.0 \%$ to motivate health professionals and patients to constantly manage blood glucose levels [9, 10]. Despite the numerous advances achieved in diabetes control and evaluation, the management of such a complex disease remains challenging. Recent epidemiological data from various regions of the world show most patients with diabetes are not controlled to recommended $\mathrm{HbA}_{1 \mathrm{c}}$ targets [11-21]. In addition, estimates of prevalence of inadequate glycaemic control vary widely, in part due to differences in diabetes type, populations surveyed, methods used to collect data, and goals of glycated haemoglobin $\left(\mathrm{HbA}_{1 \mathrm{c}}\right)$.

Information about the epidemiology of diabetes in Brazil is scarce and limited. According to a Brazilian study [22], diabetes is the fifth most common reason for hospitalizations and ranks among the 10 major causes of mortality [22]. Thus, diabetes is a major problem in Brazil, with an impact on public heath comparable to that in more developed countries. Knowledge on glycaemic control is of great relevance for planning healthcare programs targeting improved diabetes control. The aim of this study was to estimate the prevalence of inadequate glycaemic control and its correlates in a large multicentre survey of adult patients with type 1 or type 2 diabetes in Brazil.

\section{Materials and methods}

Setting and participants

This was a cross-sectional and nationwide survey conducted from February 2006 to March 2007. It was designed to obtain detailed information about glycaemic control and its determinants in the largest possible sample of diabetic adults living in urban areas in Brazil. Study design and reporting format are in accordance with the recommended STROBE (Strengthening the Reporting of Observational Studies in Epidemiology) guidelines [23]. As it was not feasible to contact patients directly, the study was based on outpatient diabetes clinics. These centres were located in 10 cities belonging to four Brazilian regions, as follows: Southeast (Belo Horizonte, Campinas, Rio de Janeiro, and São Paulo), South (Curitiba and Porto Alegre), Mid-west (Brasília), and Northeast (Salvador, Fortaleza, and Recife).
The cities included were the largest in their respective regions and nine of them are ranked among the most populous municipalities in Brazil. For the recruitment of diabetes centres, we asked the Brazilian Diabetes Association to identify in each of the participating cities a list of candidate centres, to be chosen from those with longer experience in epidemiological research and where at least 300 adult patients with diabetes were followed per month. According to these criteria, each city contributed with two centres for the sampling of the study participants. All 20 centres invited joined the study; they were classified as a university-affiliated hospital (5), a general public hospital (11), or not-for-profit private hospital (4).

\section{Study population}

We selected a sample of all consecutive patients with diabetes mellitus attending each participating clinic during a 30-day period. Eligible cases were adults aged 18 years or older, who had been previously diagnosed by a physician with either type 1 or type 2 diabetes before the survey. Patients who had participated in an intervention trial in the previous 3 months and women who reported a history of diabetes only during pregnancy were not included. Each centre was asked to recruit at least 150 patients. Overall, the response rate was $84 \%$ (ranging from 78 to $95 \%$ ). All participants provided written informed consent, and the study protocol was approved by Ethical Review Boards in each respective city.

\section{Data and specimens collection}

A structured questionnaire was administered in person by trained and certified interviewers, not part of the study centre staff. A team of study interviewers was hired and trained by one of the investigators (EDM) in each participating centre. They were given an orientation on the protocol and specific details concerning participation in the study. Prior to study commencement, they all carried out practice sessions with authentic respondents. These preliminary interviews were observed and critiqued by the investigators.

The study questionnaire sought information about diabetes history and main characteristics of each patient. This included self-reported data on socio-demographic and disease factors (age, sex, educational level, marital status, duration of diabetes, number of diabetes-related disorders, etc.); clinical parameters (fasting blood glucose, $\mathrm{HbA}_{1 \mathrm{c}}$, body mass index [BMI], and blood pressure); and factors related to treatment processes such as actual treatment for diabetes, adherence to treatment, and access to multi professional care (defined as health care delivered by a team comprised by at least, an Endocrinologist or diabetes 
specialist, a Nurse, and a Dietitian or Nutritionist). In addition, we also gathered information on self-perception of glycaemic control (using a scale with four levels: poor, fair, good, and very good), and satisfaction with current diabetes treatment (using a single global question: "If you were to spend the rest of your life with your diabetes treatment the way it is today, how would you feel about this? Very satisfied, somewhat satisfied, neither dissatisfied nor satisfied, somewhat dissatisfied, or very dissatisfied"). The questionnaire was piloted on a sample of volunteer patients to refine the wording of items and ensure clarity of the text. All items were assessed for face validity by health survey experts. The individual interviews lasted an average $20-25 \mathrm{~min}$, and the sessions occurred in a private room.

A peripheral blood sample was collected for the measurement of $\mathrm{HbA}_{1 \mathrm{c}}$ in every patient. All measurements of $\mathrm{HbA}_{1 \mathrm{c}}$ were made with an automated high-performance liquid chromatography (Variant Turbo-BioRad) in a central laboratory. The normal value range is $4.0-6.0 \%$.

Statistical analysis

All collected data were double-entered into a computerized database using a word processing, database, and statistics program (EPI INFO version 3.04d, centres for Disease Control \& Prevention, USA; World Health Organization, Geneva, Switzerland) with custom-designed algorithms and cross-checks to verify for correctness and internal consistency. The number and percent of diabetic patients who achieved glycaemic control were calculated using a cutpoint $\mathrm{HbA}_{1 \mathrm{c}}<7.0 \%$, as defined in the American Diabetes Association standards of medical care for persons with diabetes [24]. The values of $\mathrm{HbA}_{1 \mathrm{c}}$ were also classified into three arbitrary categories: $<7.0 \%, 7.0-8.9 \%$ and $\geq 9.0 \%$. The data presented were stratified by diabetes type ( 1 or 2 ) and by diabetes duration ( $<5$ years and $\geq 5$ years). In some analysis, the data on type 2 diabetes were further stratified by therapeutic regimen in two categories: insulintreated and non-insulin-treated. Basic descriptive statistics and frequency calculations were performed on all variables; a chi-square test was used to assess differences in answers by categories of stratifying variables, with statistical significance at 5\%. All statistics analyses were performed using the " $\mathrm{R}$ " statistical software (Version 2.5.0; The $\mathrm{R}$ Foundation for Statistical Computing, Vienna, Austria).

\section{Results}

Overall 6,701 patients were included in this survey, 979 (15\%) with type 1 and 5,692 (85\%) with type 2 diabetes.
The characteristics of the study participants are shown in Table 1. The age ranged from 18 to 98 years, approximately $40 \%$ of the patients with type 1 diabetes were younger than 35 years, whereas almost all patients with type 2 diabetes were 35 years or older. Most of the study participants were females, married or living with a partner, white, and had attained primary school education or less, regardless of diabetes type. The distribution of BMI categories among the patients with type 1 diabetes revealed that

Table 1 Selected characteristics (\%) of 6,671 patients, according to diabetes type, Brazil, 2006

\begin{tabular}{|c|c|c|}
\hline & \multicolumn{2}{|l|}{ Diabetes } \\
\hline & $\begin{array}{l}\text { Type } 1 \\
(n=979)\end{array}$ & $\begin{array}{l}\text { Type } 2 \\
(n=5,692)\end{array}$ \\
\hline \multicolumn{3}{|l|}{ Age in years } \\
\hline$<25$ & 18.6 & 0.2 \\
\hline $25-34$ & 21.0 & 0.8 \\
\hline $35-44$ & 21.9 & 5.6 \\
\hline $45-54$ & 19.6 & 21.5 \\
\hline $55-64$ & 13.8 & 34.7 \\
\hline$\geq 65$ & 5.1 & 37.2 \\
\hline Female & 63.8 & 66.5 \\
\hline \multicolumn{3}{|l|}{ Current marital status } \\
\hline Married/living with partner & 46.4 & 58.5 \\
\hline Single, never married & 39.9 & 14.2 \\
\hline Divorced/separated & 7.5 & 8.9 \\
\hline Widowed & 6.2 & 18.4 \\
\hline \multicolumn{3}{|l|}{ Racial/ethnic background } \\
\hline White & 49.9 & 45.2 \\
\hline Mixed & 35.3 & 41.1 \\
\hline Black & 12.7 & 12.3 \\
\hline Other & 2.1 & 1.4 \\
\hline \multicolumn{3}{|l|}{ Education } \\
\hline Primary school or less & 40.8 & 72.7 \\
\hline Secondary/high school & 43.4 & 18.7 \\
\hline At least some college & 15.8 & 8.6 \\
\hline \multicolumn{3}{|l|}{ Body Mass Index $\left(\mathrm{Kg} / \mathrm{m}^{2}\right)$} \\
\hline Underweight $(\leq 18.5)$ & 4.4 & 1.6 \\
\hline Normal weight (18.6-24.9) & 47.6 & 28.2 \\
\hline Overweight (25.0-29.9) & 32.6 & 39.8 \\
\hline Obese (30.0-39.9) & 13.6 & 27.9 \\
\hline Morbidly obese $(\geq 40.0)$ & 1.8 & 2.5 \\
\hline Multi professional care ${ }^{\mathrm{a}}$ & 83.4 & 50.5 \\
\hline \multicolumn{3}{|c|}{ Number of diabetes-related complications } \\
\hline None & 34.1 & 24.0 \\
\hline 1 & 25.7 & 30.9 \\
\hline 2 & 20.6 & 25.1 \\
\hline$\geq 3$ & 19.6 & 20.0 \\
\hline
\end{tabular}

a Comprised at least: an Endocrinologist (or diabetes specialist), a Nurse, and a Dietitian (or Nutritionist) 
$47.6 \%$ were classified as normal weight and $15.4 \%$ as obese compared to 28.2 and $30.4 \%$ among the patients with type 2 diabetes, respectively. Health care delivered by a multi professional team was reported more often by patients with type 1 diabetes $(83.4 \%)$ than by patients with type 2 diabetes $(50.5 \%)$.

The prevalence of diabetic patients with inadequate glycaemic control $\left(\mathrm{HbA}_{1 \mathrm{c}} \geq 7.0 \%\right)$ was $76 \% \quad(5,044 /$ 6,671). Table 2 shows the frequency distribution of $\mathrm{HbA}_{1 \mathrm{c}}$ values in the population studied according to diabetes type and duration. Poor glycaemic control was more common in patients with type 1 diabetes (90\%) than in those with type 2 (73\%), $P<10^{-3}$. However, the distribution of $\mathrm{HbA}_{1 \mathrm{c}}$ values in patients with type 2 diabetes (insulin-treated) resembled that found in type 1 patients; whereas patients with type 2 diabetes (non-insulin-treated) were more likely to have a higher prevalence of adequate glycaemic control $(35.7 \%)$ when compared to patients with type $1(10.4 \%)$ or type 2 (insulin-treated) $(9.7 \%), P<10^{-3}$. After stratifying the data by diabetes duration, patients with either diabetes type 1 or 2 lasting 5 years or more were more likely to have worse control than those whose diabetes started $<5$ years (Table 2).

The frequency distribution for categories of $\mathrm{HbA}_{1 \mathrm{c}}$ values by selected characteristics and diabetes type is summarized in Table 3. There was no significant difference in glycaemic control according to gender, except for type 2 patients (insulin-treated), where females were nearly twice more likely to have adequate glycaemic control (13.1\%) than males $(7.8 \%)(P<0.001)$. Patients with type 1 diabetes or with type 2 diabetes (insulin-treated) cared by a multi professional team were less likely to present $\mathrm{HbA}_{1 \mathrm{c}}$ values in the highest categories than those receiving nonspecialist care (Table 3). The self-perception of glycaemic control was associated with $\mathrm{HbA}_{1 \mathrm{c}}$ levels, regardless of diabetes type. Hence, patients who perceived their glycaemic control to be "poor" or "fair" were more likely to fall in the top category of $\mathrm{HbA}_{1 \mathrm{c}}$ values, conversely, patients perceiving their glycaemic control to be "good" or "very good" were more likely to have adequate glycaemic control and to be classified in the lower category of $\mathrm{HbA}_{1 \mathrm{c}}$ values $(<7.0 \%)$. Ever participating in a group or programme that promotes diabetes health education was associated with lower rates of elevated $\mathrm{HbA}_{1 \mathrm{c}}$ values in patients with type 1 diabetes, but there was no significant difference among patients with type 2 diabetes (Table 3 ).

The reported satisfaction with current diabetes treatment was directly associated with glycaemic control (Fig. 1). Diabetic patients satisfied with their treatment were more likely to have adequate glycaemic control. This was more evident in patients with type 2 diabetes (non-insulin-treated), but was also seen among patients with type 1 diabetes and type 2 diabetes (insulin-treated).

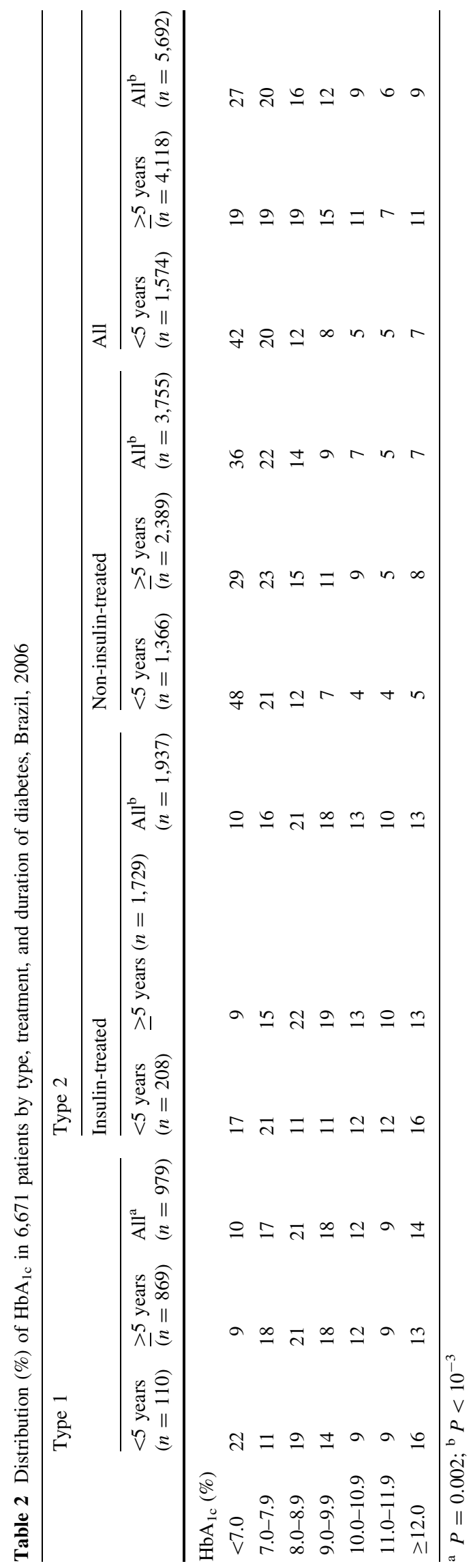




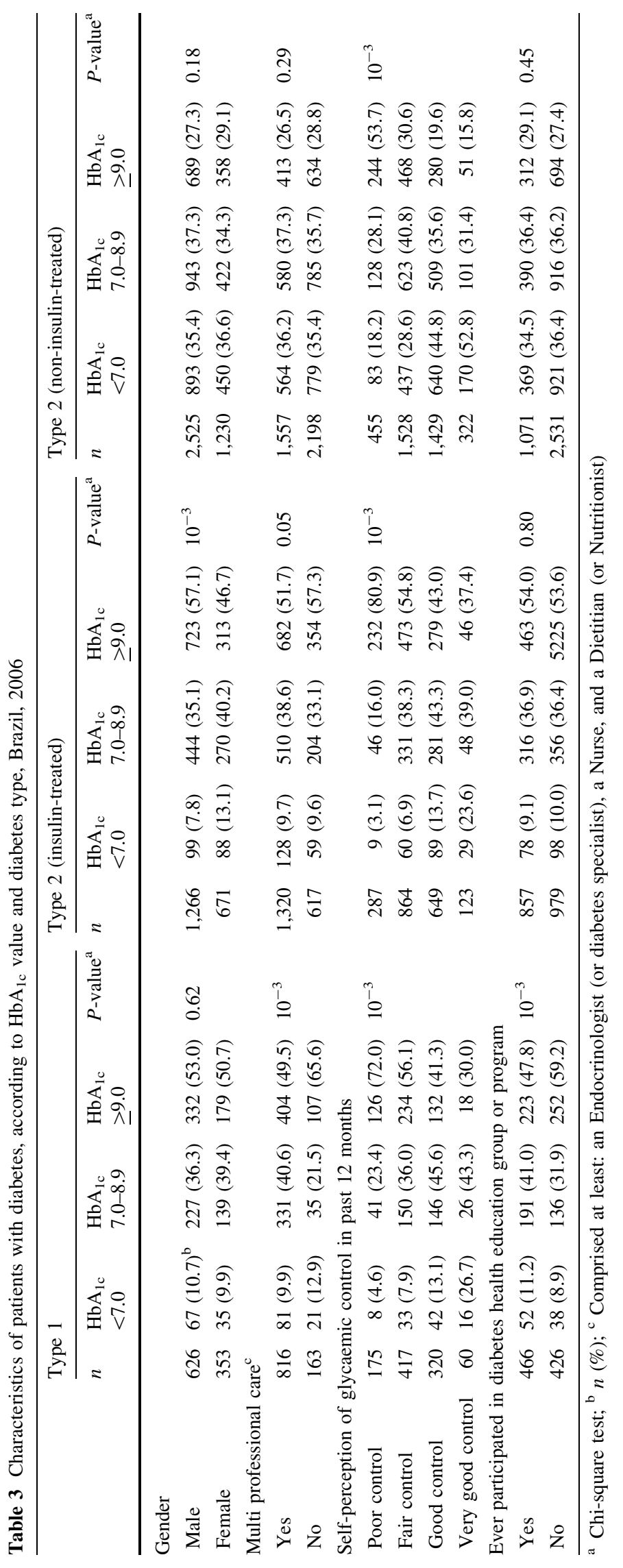




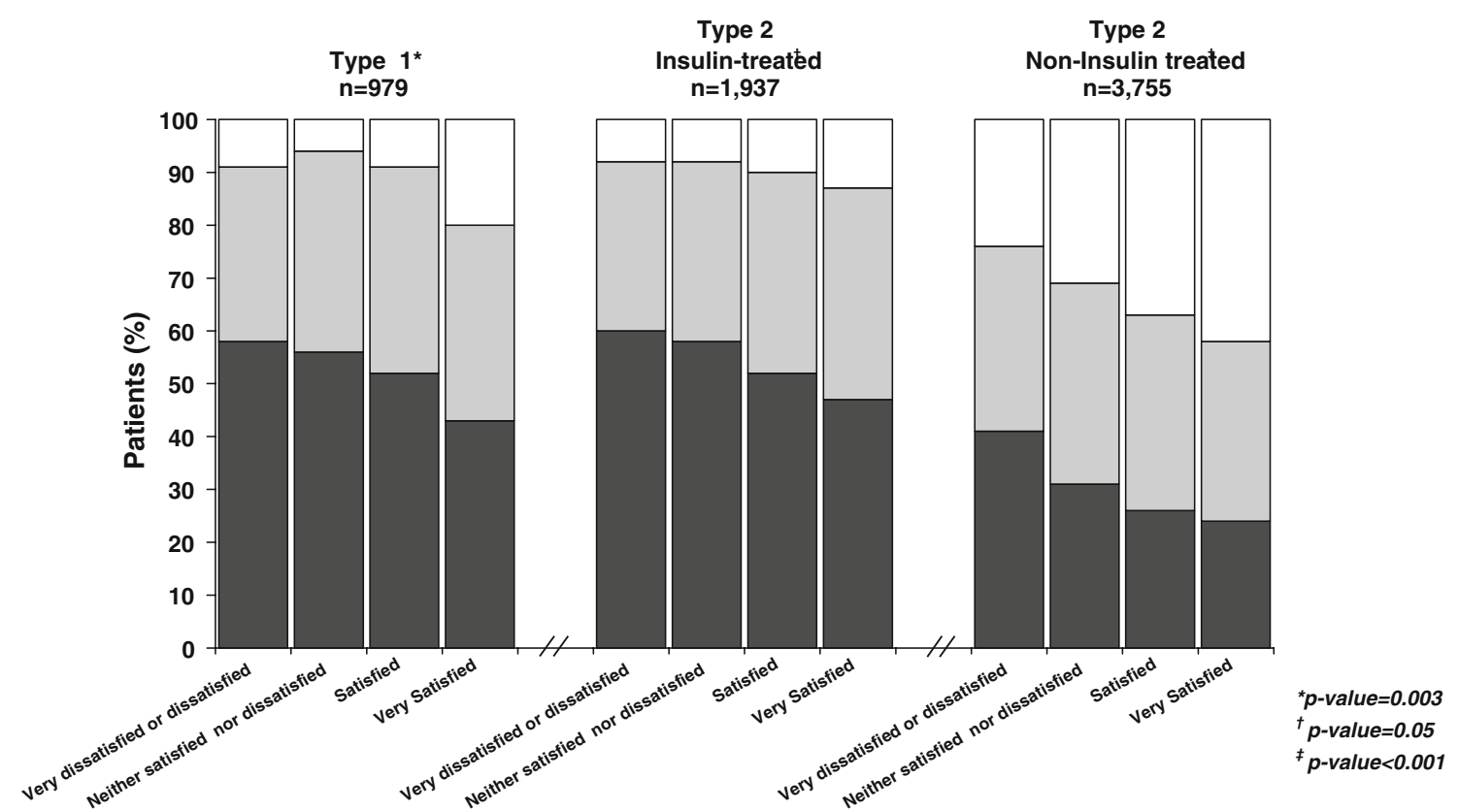

Fig. 1 Relationship between self-reported global satisfaction with diabetes treatment and distribution of $\mathrm{HbA}_{1 \mathrm{c}}$ values, according to diabetes type, Brazil, 2006

\section{Discussion}

To our knowledge, this is the largest multicentre, nationwide survey to estimate prevalence rates of inadequate glycaemic control in Brazil, and the first to evaluate these rates in patients with type 1 or type 2 diabetes. The overall prevalence of inadequate glycaemic control in our study (76\%) was high, and greater than previous estimates from studies in Germany (40\%) [18], Denmark (51\%) [14], and Kenya (61\%) [17], which also included type 1 and 2 diabetic patients.

The rates of inadequate glycaemic control were higher in patients with type 1 diabetes $(90 \%)$ than in patients with type 2 diabetes (73\%). Among the latter group, patients without insulin in their therapeutic regimen had lower rates of poor glycaemic control (64\%). While patients using insulin presented a prevalence of inadequate glycaemic control (90\%) similar to that found in patients with type 1 diabetes. These differences changed after we stratify the data by diabetes duration, but even among patients at earlier stage of diabetes ( $<5$ years duration) insulin treatment is associated with worse control when compared to diet alone or combined with oral treatment, possibly due to more severe and more difficult to control diabetes in the former patients. Furthermore, patients using oral treatment (the major option in the group "non-insulin-treated") have a more simple to administer treatment option, which tends to be more effective under the conditions of daily life.

Our rates of inadequate glycaemic control in patients with type 2 diabetes are higher than those reported in the same type of diabetic patients in the United States, where estimates derived from the National Health and Nutrition Examination Survey [NHANES] were 63\% (1999-2000), 51\% (2001-2002), and 43\% (2003-2004) [25]. Similarly, reports from Canada (49\%) [13], and the Netherlands (42\%) [26] also revealed rates of poor glycaemic control in type 2 diabetes lower than ours. However, recent surveys in patients with type 2 diabetes in the United Kingdom [UK] $(N=10,663)$ [12] and Canada $(N=5,569)$ [20] provided estimates of inadequate glycaemic control closer to ours, 76 and $73 \%$, respectively. Although these variations across studies may be true, they may also be due to differences in populations surveyed, methods of data collection, measurements of $\mathrm{HbA}_{1 \mathrm{c}}$, and definitions of $\mathrm{HbA}_{1 \mathrm{c}}$ cutpoint for adequate glycaemic control.

In our data, there was no significant difference in glycaemic control by gender, except among patients with type 2 diabetes (insulin-treated), where women achieved a better glycaemic control. In contrast, a study in a Pakistani moslem diabetic population in Manchester, UK, women were worse than men in performing regular glucose measurements, in managing persistent hyperglycaemia, and had poorer glycaemic control overall [27]. Results from a survey in Mexico have suggested that women have several social disadvantages, deterioration of healthy life, poor self-care, and lack of solidarity that increases their vulnerability to reach glycaemic control successfully [28]. However, several studies have failed to show significant gender differences related to self-care and control of type 2 diabetes $[12,20,25,26]$. 
We found that health care delivered by a multi professional team was associated with improved glycaemic control in patients with type 1 diabetes or with type 2 diabetes (insulin-treated). Our results are consistent with previous studies comparing primary with specialist diabetes care [16, 20, 26, 29]. In the Pittsburgh Epidemiology of Diabetes Complications Study, specialist care was associated with higher levels of participation in diabetes self-care practices and a lower $\mathrm{HbA} 1$ level, but in the multivariate analyses the lower $\mathrm{HbA} 1$ levels observed in patients receiving specialist care were restricted to patients with an annual income $>\$ 20,000$ [30]. Possible explanations for the better $\mathrm{HbA}_{1 \mathrm{c}}$ seen with prior multi professional care include greater access to other health care providers such as nurse educators or dietitians, greater focus on glycaemia management, or more aggressive use of glucose-lowering medications by specialists.

There is evidence that poor numeracy skills are common in patients with diabetes, and that low diabetes-related numeracy skills are associated with fewer self-management behaviours, and possibly poorer glycaemic control [31]. Diabetes self-management education programs are considered an essential strategy for improving health behaviors of adults with diabetes. In a study to estimate the impact of participation in a diabetes health education program on glycaemic levels, Roblin et al. [32] reported that participation significantly improved glycaemic levels between baseline and follow-up periods. Our findings suggest that participation in a diabetes health education programme is associated with lower $\mathrm{HbA}_{1 \mathrm{c}}$ values in patients with type 1 diabetes, but we failed to show that among patients with type 2 diabetes. However, our assessment was limited to whether the patient had ever participated in a diabetes health education program, and did not differentiate subjects according to the amount of time and/or effort dedicated to such programs.

Among the participants in our survey, self-perception of glycaemic control was associated with $\mathrm{HbA}_{1 \mathrm{c}}$ levels. That is, patients who perceived their glycaemic control to be "poor" or "fair" were more likely to present higher $\mathrm{HbA}_{1 \mathrm{c}}$ values. This awareness may result from several reasons including: the patients experiencing adverse symptoms associated with hyperglycaemia, the patients' knowledge about their actual adherence to diet and antidiabetic medication, and/or the patients' information of their recent $\mathrm{HbA}_{1 \mathrm{c}}$ results. Unsurprisingly, we also found that global satisfaction with current diabetes treatment was associated with improved glycaemic control. It has been shown that improvement in patient convenience provides better compliance with therapeutic regimen and greater patient satisfaction, and this in turn leads to better glycaemic control [33-36].
Strengths and limitations

The distinctive strengths of this study are the large multicentre sample, the collection of data by trained and certified interviewers (not part of the staff at each study centre), the measurement of $\mathrm{HbA}_{1 \mathrm{c}}$ by a reliable method in a central laboratory, and the high response rate $(84 \%)$. This high response was accomplished by rigorous training of interviewers, who were selected based on interpersonal skills displayed in previous surveys. Despite that, one limitation is that the study was centre based, and while our sample might be representative of patients with diabetes attending health care facilities in Brazil, it may not be representative of the whole population of Brazilian patients with diabetes.

\section{Conclusion}

Despite clinical evidence supporting tight control of diabetes and increased awareness of the benefits of improved metabolic control, we found that few diabetic patients in Brazil met recommended glycaemic control targets. A large proportion of patients with either type 1 or type 2 diabetes were inadequately controlled. This may contribute to increased rates of diabetic complications, which will impact health care costs. Our data support the public health message of implementation of early, aggressive management of diabetes. The reasons for a worse metabolic control in patients treated with insulin are not evident in our data. One may argue that poor adherence to insulin and/or some degree of inertia to apply the best currently available treatment regime in patients who need insulin might account for this finding.

Acknowledgments The authors wish to thank Diagnostics of America (DASA) Laboratory team and the Brazilian Diabetes Society for their valuable support during the development and conduction of the study. We also thank Mrs. Fatima Gonçalves for her assistance in planning the logistics and for the data quality monitoring. This research was partially presented in abstract form at the 68th Scientific Session of the American Diabetes Association, San Francisco, CA, 2008. The Brazilian Study of Diabetes Control was funded by Pfizer Inc., Brazil.

Open Access This article is distributed under the terms of the Creative Commons Attribution Noncommercial License which permits any noncommercial use, distribution, and reproduction in any medium, provided the original author(s) and source are credited.

\section{Appendix}

The following is a list of co-authors, the members of the Brazilian Diabetes Investigators' Group: Adriana C. Forti, MD; Célio C. Borges, MD; Débora V. Soares, MD; Edson 
P. Brum, MD; Elza M. S. Constantino, MD; Francisco A. Oliveira, MD; Freddy Eliaschewitz, MD; Hermelinda Pedrosa, MD; Jorge Gross, MD; José E. P. Oliveira, MD; Lucia Cordeiro, MD; Lúcia P. E. Souza, MD; Marcia Nery, MD; Marcos Tambascia, MD; Maria C. C. de Almeida, PhD; Maria R. Calsolari, MD; Reinaldo B. M. Machado, MD; Reine Chaves, MD; Rosane Kupfer, MD; Ruy Lyra, MD; Saulo Cavalcante, MD; and Silmara Leite, MD.

\section{References}

1. Narayan KM, Gregg EW, Fagot-Campagna A, Engelgau MM, Vinicor F (2000) Diabetes - a common, growing, serious, costly, and potentially preventable public health problem. Diabetes Res Clin Pract 50(Suppl 2):S77-S84

2. Wild S, Roglic G, Green A, Sicree R, King H (2004) Global prevalence of diabetes: estimates for the year 2000 and projections for 2030. Diabetes Care 27:1047-1053

3. Yach D, Stuckler D, Brownell KD (2006) Epidemiologic and economic consequences of the global epidemics of obesity and diabetes. Nat Med 12:62-66

4. Park JS, Cho MH, Nam JS, Ahn CW, Cha BS, Lee EJ et al (2009) Visceral adiposity and leptin are independently associated with C-reactive protein in Korean type 2 diabetic patients. Acta Diabetol. doi:10.1007/s00592-009-0125-4

5. Deepa R, Pradeepa R, Shanthirani CS, Mohan V (2004) Association of hypertension with cluster of insulin resistance syndrome factors: the Chennai Urban Population Study (CUPS-12). Acta Diabetol 41:49-55

6. Raman R, Rani PK, Gnanamoorthy P, Sudhir RR, Kumaramanikavel G, Sharma T (2009) Association of obesity with diabetic retinopathy: Sankara Nethralaya Diabetic Retinopathy Epidemiology and Molecular Genetics Study (SN-DREAMS Report no. 8). Acta Diabetol. doi:10.1007/s00592-009-0113-8

7. No Authors (1993) The effect of intensive treatment of diabetes on the development and progression of long-term complications in insulin-dependent diabetes mellitus. The Diabetes Control and Complications Trial Research Group. N Engl J Med 329:977-86

8. No Authors (1998) Intensive blood-glucose control with sulphonylureas or insulin compared with conventional treatment and risk of complications in patients with type 2 diabetes (UKPDS 33). UK Prospective Diabetes Study (UKPDS) Group. Lancet 352:837-53

9. American Association of Clinical Endocrinologists (2002) American College of Endocrinology consensus statement on guidelines for glycemic control. Endocr Pract 8:5-11

10. Ahmad Khan H (2007) Clinical significance of HbA1c as a marker of circulating lipids in male and female type 2 diabetic patients. Acta Diabetol 44:193-200

11. Ben Abdelaziz A, Soltane I, Gaha K, Thabet H, Tlili H, Ghannem $\mathrm{H}$ (2006) Predictive factors of glycemic control in patients with type 2 diabetes mellitus in primary health care. Rev Epidemiol Sante Publique 54:443-452

12. Fox KM, Gerber Pharmd RA, Bolinder B, Chen J, Kumar S (2006) Prevalence of inadequate glycemic control among patients with type 2 diabetes in the United Kingdom general practice research database: a series of retrospective analyses of data from 1998 through 2002. Clin Ther 28:388-395

13. Harris SB, Ekoe JM, Zdanowicz Y, Webster-Bogaert S (2005) Glycemic control and morbidity in the Canadian primary care setting (results of the diabetes in Canada evaluation study). Diabetes Res Clin Pract 70:90-97
14. Jorgensen LG, Petersen PH, Heickendorff L, Moller HJ, Hendel $\mathrm{J}$, Christensen $\mathrm{C}$ et al (2005) Glycemic control in diabetes in three Danish counties. Clin Chem Lab Med 43:1366-1372

15. Koro CE, Bowlin SJ, Bourgeois N, Fedder DO (2004) Glycemic control from 1988 to 2000 among U.S. adults diagnosed with type 2 diabetes: a preliminary report. Diabetes Care 27:17-20

16. Leinung MC, Gianoukakis AG, Lee DW, Jeronis SL, Desemone J (2000) Comparison of diabetes care provided by an endocrinology clinic and a primary-care clinic. Endocr Pract 6:361-366

17. Otieno CF, Kariuki M, Ng'ang'a L (2003) Quality of glycaemic control in ambulatory diabetics at the out-patient clinic of Kenyatta National Hospital, Nairobi. East Afr Med J 80:406-410

18. Pittrow D, Stalla GK, Zeiher AM, Silber S, Marz W, Pieper L et al (2006) Prevalence, drug treatment and metabolic control of diabetes mellitus in primary care. Med Klin (Munich) 101:635644

19. Saydah SH, Fradkin J, Cowie CC (2004) Poor control of risk factors for vascular disease among adults with previously diagnosed diabetes. JAMA 291:335-342

20. Shah BR, Hux JE, Laupacis A, Mdcm BZ, Austin PC, van Walraven C (2005) Diabetic patients with prior specialist care have better glycaemic control than those with prior primary care. J Eval Clin Pract 11:568-575

21. Tutuncuoglu P, Sarac F, Saygili F, Ozgen AG, Yilmaz C, Tuzun M (2008) Diabetes and impaired glucose tolerance prevalences in Turkish patients with impaired fasting glucose. Acta Diabetol 45:151-156

22. Malerbi DA, Franco LJ (1992) Multicenter study of the prevalence of diabetes mellitus and impaired glucose tolerance in the urban Brazilian population aged 30-69 yr. The Brazilian Cooperative Group on the Study of Diabetes Prevalence. Diabetes Care 15:1509-1516

23. von Elm E, Altman DG, Egger M, Pocock SJ, Gotzsche PC, Vandenbroucke JP (2007) The Strengthening the Reporting of Observational Studies in Epidemiology (STROBE) statement: guidelines for reporting observational studies. Lancet 370:14531457

24. American Diabetes Association (2003) Standards of medical care for patients with diabetes mellitus. Diabetes Care 26(Suppl 1):S33-50

25. Hoerger TJ, Segel JE, Gregg EW, Saaddine JB (2008) Is glycemic control improving in U.S. adults? Diabetes Care 31:81-86

26. Goudswaard AN, Stolk RP, Zuithoff P, Rutten GE (2004) Patient characteristics do not predict poor glycaemic control in type 2 diabetes patients treated in primary care. Eur $\mathrm{J}$ Epidemiol 19:541-545

27. Hawthorne K, Tomlinson S (1999) Pakistani moslems with Type 2 diabetes mellitus: effect of sex, literacy skills, known diabetic complications and place of care on diabetic knowledge, reported self-monitoring management and glycaemic control. Diabet Med 16:591-597

28. Salcedo-Rocha AL, Garcia de Alba-Garcia JE, Frayre-Torres MJ, Lopez-Coutino B (2008) Gender and metabolic control of type 2 diabetes among primary care patients. Rev Med Inst Mex Seguro Soc 46:73-81

29. Tabak AG, Tamas G, Zgibor J, Wilson R, Becker D, Kerenyi Z et al (2000) Targets and reality: a comparison of health care indicators in the U.S. (Pittsburgh Epidemiology of Diabetes Complications Study) and Hungary (DiabCare Hungary). Diabetes Care 23:1284-1289

30. Zgibor JC, Songer TJ, Kelsey SF, Weissfeld J, Drash AL, Becker $\mathrm{D}$ et al (2000) The association of diabetes specialist care with health care practices and glycemic control in patients with type 1 diabetes: a cross-sectional analysis from the Pittsburgh epidemiology of diabetes complications study. Diabetes Care 23:472476 
31. Cavanaugh K, Huizinga MM, Wallston KA, Gebretsadik T, Shintani A, Davis D et al (2008) Association of numeracy and diabetes control. Ann Intern Med 148:737-746

32. Roblin DW, Ntekop E, Becker ER (2007) Improved intermediate clinical outcomes from participation in a diabetes health education program. J Ambul Care Manag 30:64-73

33. Ishii H, Anderson JH Jr, Yamamura A, Takeuchi M, Ikeda I (2008) Improvement of glycemic control and quality-of-life by insulin lispro therapy: assessing benefits by ITR-QOL questionnaires. Diabetes Res Clin Pract 81:169-178

34. Chisalita SI, Lindstrom T, Eson Jennersjo P, Paulsson JF, Westermark GT, Olsson AG et al (2009) Differential lipid profile and hormonal response in type 2 diabetes by exogenous insulin aspart versus the insulin secretagogue repaglinide, at the same glycemic control. Acta Diabetol 46:35-42

35. Rosenstock J, Cappelleri JC, Bolinder B, Gerber RA (2004) Patient satisfaction and glycemic control after 1 year with inhaled insulin (Exubera) in patients with type 1 or type 2 diabetes. Diabetes Care 27:1318-1323

36. De Mattia G, Laurenti O, Moretti A (2009) Comparison of glycaemic control in patients with type 2 diabetes on basal insulin and fixed combination oral antidiabetic treatment: results of a pilot study. Acta Diabetol 46:67-73 